\title{
Design, synthesis and potential CNS activity of some novel 1-(4-substituted-phenyl)-3-(4-oxo-2-propyl-4H-quinazolin-3-yl)-urea
}

\author{
Sushil K. Kashaw,* Varsha Kashaw, Pradeep Mishra, and N. K. Jain \\ *Pharmaceutical Chemistry Division, Department of Pharmaceutical Sciences, Dr. H. S.Gour \\ University, Sagar, (M.P.), India \\ E-mail: sushilkashaw@gmail.com
}

\begin{abstract}
Twelve new 1-(4-substituted-phenyl)-3-(4-oxo-2-propyl-4H- quinazolin-3-yl)-urea were synthesized and screened for CNS depressant, sedative-hypnotic and phenobarbitone induced hypnosis potentiation test. Spectroscopic data and elemental analysis were consistent with the newly synthesized compounds. All except H1 and H6 showed more than $40 \%$ decrease in locomotor activity after $1 \mathrm{~h}$ of compound administration via actophotometer screen. CNS depressant activity screened with the help of forced swim method resulted into some potent compounds. Except for H3, H6 and H7 other tested compounds were found to exhibit potent CNS depressant activity as indicated by increased immobility time. No significant percentage increase in the sleeping time was observed in any of the synthesized compounds evaluated by phenobarbitone induced hypnosis potentiation test. It can be concluded that newly synthesized compounds possessed sedative-hypnotic and CNS depressant activities at a significant level.
\end{abstract}

Keywords: 4(3H)-Quinazolinones, CNS depressant activity, phenobarbitone induced hypnosis potentiation test

\section{Introduction}

One of the most frequently encountered heterocyclic compound in medicinal chemistry is $4(3 H)$ quinazolinone with wide applications including antibacterial, antifungal, anticonvulsant, antiinflammatory activities ${ }^{1-4}$. A literature survey revealed that the presence of a substituted aromatic ring at position 3 and a methyl group at position 2 are a necessary requirement for central nervous system (CNS) depression and anticonvulsant activities. Modification of the methyl group by some other chemical moiety yielded structural analogues with potent CNS activity. Various hypotheses were analyzed before we undertook chemical synthesis of the proposed compounds. First hypothesis was inspired from the $4(3 H)$-quinazolinone nucleus containing well known sedative-hypnotic Methaqualone (2-methyl-3-o-tolyl-4(3H)-quinazolinone). Chemical 
modifications at the second and third position of this agent have led to the generation of many CNS active agents. Second hypothesis was based upon the work of Boltz et al. ${ }^{5}$ and Wolfe et $a l .{ }^{6}$. According to this hypothesis $-\mathrm{CH}_{3}$ at second position of 4(3H)-quinazolinone is not always necessary for the CNS activity and other groups when placed at this position can also lead to potent CNS active agents. Figure 1a represents the similarities between methaqualone and our designed compounds. Third hypothesis was based upon the results and interpretations of our previous study on CNS activity of 2,3-disubstituted 4(3H)-quinazolinones in which we discovered more potent sedative-hypnotic and CNS depressant compounds as compared to anticonvulsant $^{7,8}$ (Figure 1b). With the entire mentioned hypothesis as background the present work was carried out on two objectives: the first was the synthesis of the hybrid compounds possessing mentioned molecular features; the second objective was the sedative-hypnotic, CNS depressant and phenobarbitone induced hypnosis potentiation screening of the synthesized compounds. In hope of getting synergistic response of 4(3H)-quinazolinone nucleus, placement of substituted semicarbazides at third position and chemically modifying second position of $4(3 H)$-quinazolinone (substituting $-\mathrm{C}_{3} \mathrm{H}_{7}$ ), the present paper reports on the synthesis, CNS depressant and behavioral study of twelve 2, 3- disubstituted-quinazolin-4(3H)-one.
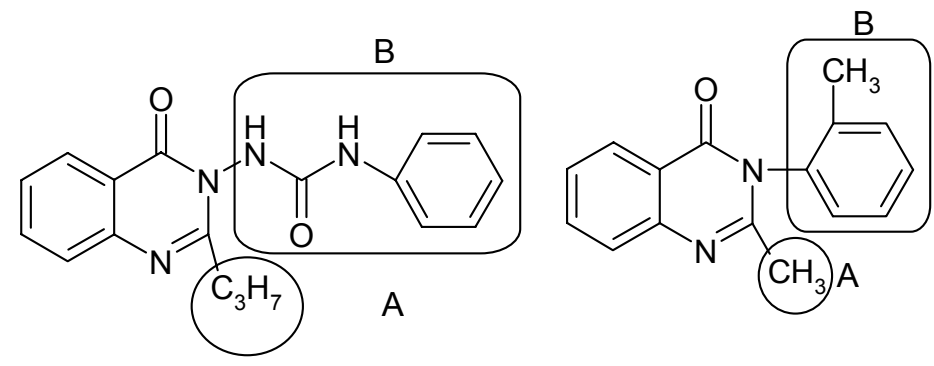

Figure 1a. Comparative pictorial representation of the proposed hypothesis and methaqualone.

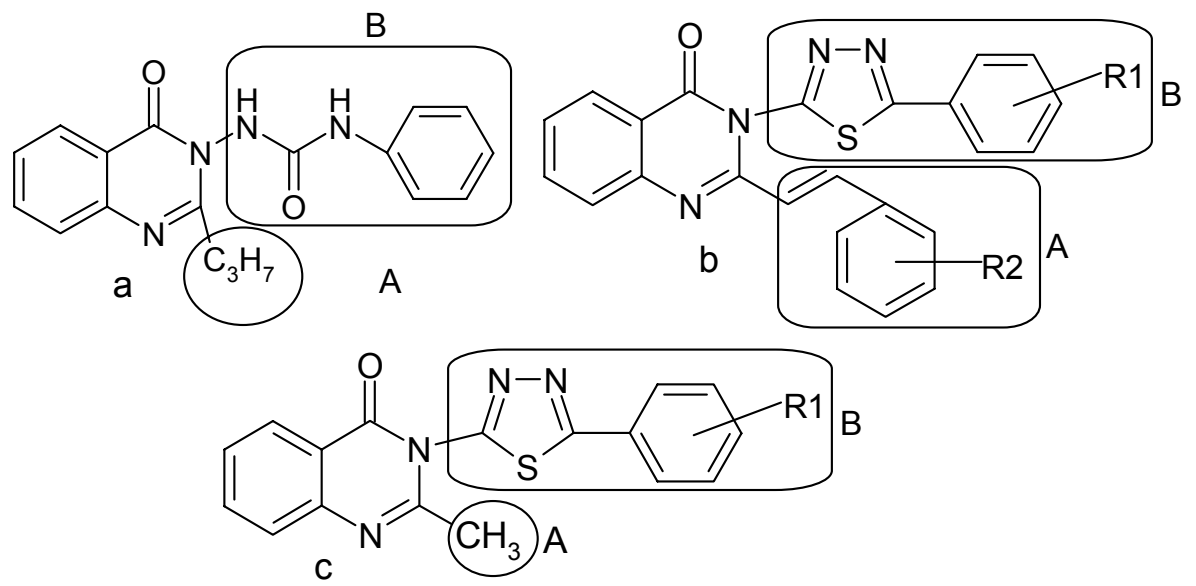

Figure 1b. Comparative pictorial representation of the proposed hypothesis (a) and previously reported compounds by same group (b and $c)$. 


\section{Results and Discussion}

Almost all the quinazolinone analogs showed potent sedative-hypnotic and CNS depressant activity. In the behavioral study using actophotometer scoring technique, the entire synthesized compounds showed decrease in locomotor activity where $37 \%$ was the lowest and $52 \%$ was the maximal decrease in locomotor activity when compared to phenytoin as reported in Table 1.

Table 1. Behavioral study of 1-(4-substituted-phenyl)-3-(4-oxo-2-propyl-4H-quinazolin-3-yl)urea (H1-H12)

\begin{tabular}{|c|c|c|c|c|}
\hline \multirow[t]{3}{*}{ Compound $^{\mathrm{a}}$} & \multicolumn{3}{|c|}{ Activity score } & \multirow{3}{*}{$\begin{array}{c}\% \\
\text { inhibition }\end{array}$} \\
\hline & \multirow[t]{2}{*}{ Control (24 h prior) } & \multicolumn{2}{|c|}{ Post treatment } & \\
\hline & & $0.5 \mathrm{~h}$ after & $1 \mathrm{~h}$ after & \\
\hline H1 & $542.82 \pm 1.24$ & $429.09 \pm 1.16$ & $337.10 \pm 0.42$ & 38 \\
\hline $\mathrm{H} 2$ & $569.63 \pm 0.89$ & $496.56 \pm 0.20$ & $319.24 \pm 0.69$ & 44 \\
\hline $\mathrm{H} 3$ & $426.76 \pm 0.84$ & $400.32 \pm 0.82$ & $231.45 \pm 0.86$ & 46 \\
\hline $\mathrm{H} 4$ & $532.82 \pm 1.24$ & $480.09 \pm 1.16$ & $277.30 \pm 0.42$ & 48 \\
\hline H5 & $559.16 \pm 0.62$ & $531.33 \pm 1.26$ & $280.52 \pm 0.86$ & 50 \\
\hline H6 & $465.02 \pm 0.83$ & $404.24 \pm 0.82$ & $293.73 \pm 0.72$ & 37 \\
\hline $\mathrm{H} 7$ & $547.48 \pm 0.71$ & $510.67 \pm 0.61$ & $279.28 \pm 1.21$ & 49 \\
\hline $\mathrm{H} 8$ & $474.32 \pm 0.72$ & $448.19 \pm 0.77$ & $290.24 \pm 0.18$ & 39 \\
\hline H9 & $490.32 \pm 0.72$ & $459.19 \pm 0.77$ & $255.24 \pm 0.18$ & 48 \\
\hline $\mathrm{H} 10$ & $469.59 \pm 2.01$ & $411.21 \pm 0.87$ & $235.19 \pm 0.24$ & 52 \\
\hline H11 & $462.67 \pm 0.78$ & $429.82 \pm 1.14$ & $278.42 \pm 1.24$ & 40 \\
\hline H12 & $482.67 \pm 0.78$ & $466.82 \pm 1.14$ & $280.42 \pm 1.24$ & 42 \\
\hline Phenytoin ${ }^{\mathrm{b}}$ & $646.40 \pm 31.12$ & $551.02 \pm 12.32$ & $207.10 \pm 30.11$ & 68 \\
\hline
\end{tabular}

${ }^{\mathrm{a}}$ The compound were tested at a dose of $100 \mathrm{mg} / \mathrm{kg}$ (i.p.). ${ }^{\mathrm{b}}$ Tested at $25 \mathrm{mg} / \mathrm{kg}$ i.p.

All the compounds except $\mathrm{H} 1$ and $\mathrm{H} 6$ showed more then $40 \%$ decrease in locomotor activity $(\mathrm{p}<0.05)$ after $1 \mathrm{~h}$ of compound administration. H6 was the least potent compound and M10 was the most potent compound in the prepared series. In a similar study with forced swim pool test, the immobility time after administration of the test compounds were compared with carbamazepine (Table 4). Readings of control groups were taken individually for each compound $24 \mathrm{~h}$ prior to compound administration. 
Table 4. CNS study on 1-(4-substituted-phenyl)-3-(4-oxo-2-propyl-4H-quinazolin-3-yl)-urea (H1-H12) by forced swim pool test

\begin{tabular}{ccc}
\hline Compound $^{\mathrm{a}}$ & \multicolumn{2}{c}{ Immobility time $^{\mathrm{b}}(\mathrm{s})$} \\
& Control $(24 \mathrm{~h}$ prior $)$ & $\begin{array}{c}\text { Post treatment } \\
(60 \text { min after })\end{array}$ \\
\hline PEG & $174.67 \pm 10.72$ & $178.53 \pm 14.23 \mathrm{NS}$ \\
H1 & $140.12 \pm 5.41$ & $205.30 \pm 13.45$ \\
H2 & $117.52 \pm 6.41$ & $150.37 \pm 11.67$ \\
H3 & $152.42 \pm 8.74$ & $211.00 \pm 18.17$ \\
H4 & $90.15 \pm 14.12$ & $165.30 \pm 13.04$ \\
H5 & $118.29 \pm 8.32$ & $187.60 \pm 15.36$ \\
H6 & $128.33 \pm 9.12$ & $138.72 \pm 17.66 \mathrm{NS}$ \\
H7 & $100.43 \pm 9.45$ & $116.83 \pm 18.37 \mathrm{NS}$ \\
H8 & $67.56 \pm 17.32$ & $120.60 \pm 19.17$ \\
H9 & $187.69 \pm 15.45$ & $208.72 \pm 14.58$ \\
H10 & $102.74 \pm 17.16$ & $183.24 \pm 18.27$ \\
H1 & $144.88 \pm 13.74$ & $179.07 \pm 11.57$ \\
H12 & $127.27 \pm 16.12$ & $190.43 \pm 10.04 \mathrm{NS}$ \\
Carbamazepine & $138.12 \pm 15.03$ & $240.30 \pm 14.18$ \\
\hline
\end{tabular}

${ }^{\mathrm{a}}$ The compounds were tested at a dose of $100 \mathrm{mg} / \mathrm{kg}$ (i.p.). ${ }^{\mathrm{b}}$ Each value represent the mean $\pm \mathrm{SEM}$ of six rats significantly different from the control at $\mathrm{p}<0.05$ and NS denotes not significant at $\mathrm{p}<0.05$ (student's t test). ${ }^{\mathrm{c}}$ Tested at $30 \mathrm{mg} / \mathrm{kg}$ (i.p.).

Biological activity was also ascertained for PEG because it was used as a vehicle for the synthesized compounds. Except for H6 and H7 other tested compounds were found to exhibit potent CNS depressant activity as indicated by increased immobility time. H6 was also inactive in the sedative-hypnotic screening. These results suggest that presence of $-\mathrm{NO}_{2}$ at the para position of the phenyl urea is not beneficial for the activity. Some selected compounds (Table 5) were evaluated for the phenobarbitone induced hypnosis potentiation test. No compound was found to show significant percentage increase in sleeping time of the animals. Bulkier compounds are more lipophilic and can cross blood brain barrier to exert their effect at CNS. Methyl and ethyl substituted compounds possessed better CNS activity as compared to unsubstituted. Nitro substituted compound was inactive in all the CNS screening tests. Present study explored that substitution of substituted phenyl urea at third position and $-\mathrm{C}_{3} \mathrm{H}_{7}$ moiety at second position of $4(3 H)$-quinazolinone leads to the development of new chemical entities with potent CNS activity. 
Table 5. Phenobarbitone induced hypnosis potentiation test for some selected compounds

\begin{tabular}{ccc}
\hline Code. & $\begin{array}{c}\text { Duration of sleep in minutes } \pm \\
\text { SEM }\end{array}$ & \% increase in sleep \\
\hline H1 & $76 \pm 3.81$ & 8.8 \\
H7 & $78 \pm 5.42$ & 11.4 \\
H8 & $128 \pm 5.8$ & 13.0 \\
H9 & $88 \pm 5.55$ & 10.1 \\
H10 & $153 \pm 5.48$ & 19.6 \\
H11 & $95 \pm 4.22$ & 20.2 \\
H12 & $112 \pm 6.43$ & 16.3 \\
Phosphate buffer solution & $79 \pm 4.87$ & -- \\
(control) & & \\
\hline
\end{tabular}

Number of animal taken for the study $(n)=6$

\section{Experimental Section}

The synthesis of the target compounds was accomplished as shown in Figure 2. Synthesis of 2propyl-benzoxazin-4-one is based on the earlier reported methods. Anthranilic acid (4) was refluxed under standard conditions with butyric anhydride and then with the acetic anhydride to yield 2-propyl-benzoxazin-4-one (6). Various substituted aryl semicarbazides were synthesized according to the procedure mentioned in the literature. Substituted aniline (1) was treated with sodium cyanate in the presence of glacial acetic acid according to the known urea method ${ }^{9,10}$ to yield substituted phenyl urea (2). These substituted phenyl urea derivatives on condensation with hydrazine hydrate in ethanol under alkaline conditions provided substituted aryl semicarbazides (3). Synthesis of the target compounds were carried out according to the scheme presented in the Figure 2. Different substituted semicarbazides were refluxed in the presence of glacial acetic acid with 2-propyl-benzoxazin-4-one to yield H1-H12. The IR spectra showed the $\mathrm{C}=\mathrm{O}$ str. at 1670 $\mathrm{cm}^{-1}, \mathrm{C}=\mathrm{N}$ stretching of quinazolinone ring at $1590 \mathrm{~cm}^{-1}$. 

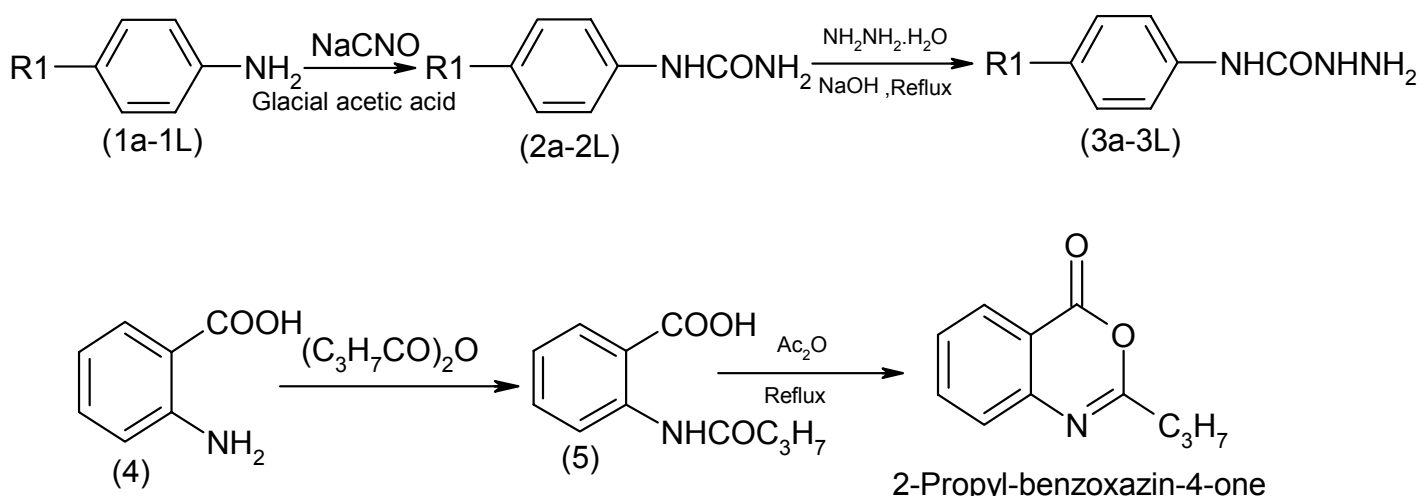

(6)

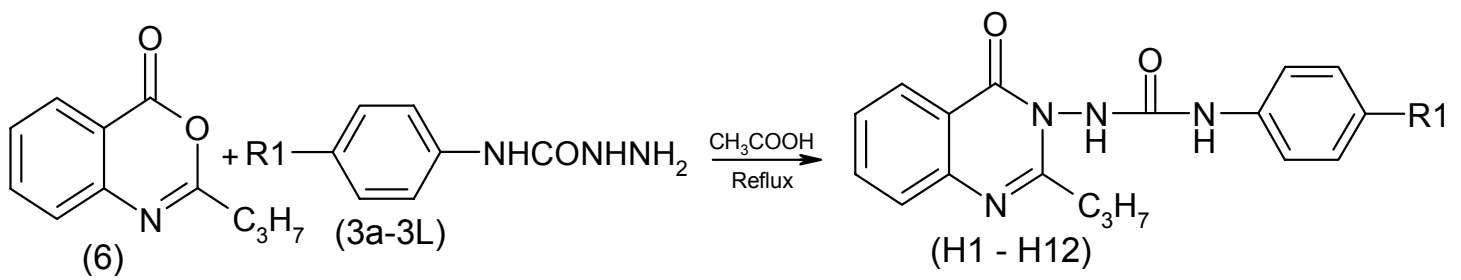

Figure 2. Scheme for the synthesis of 1-(4-substituted-phenyl)-3-(4-oxo-2-propyl-4Hquinazolin-3-yl)-urea.

The ${ }^{13} \mathrm{C}-\mathrm{NMR}$ depicted spectrum at (C-2) 163, (C-4) 166, (C-11)112 and (Cz) 156. Thin layer chromatography (TLC) was run throughout the reaction to optimize the reaction for purity and completion.

Melting points were determined in one end open capillary tubes on a Buchi 530 melting point apparatus and are uncorrected. Infrared (IR) and ${ }^{13} \mathrm{C}$ nuclear magnetic resonance $\left({ }^{13} \mathrm{CNMR}\right)$ spectra were recorded for the compounds on Perkin Elmer Spectrum RXI Spectrophotometer in $\mathrm{KBr}$ pellets and ${ }^{13} \mathrm{C}$ Advance Bruker (300 MHz) instrument, respectively. Chemical shifts are reported in parts per million (ppm) using tetramethylsilane (TMS) as an internal standard. Elemental analysis (C, H \& N) were undertaken with Elemental vario EL III Carlo Erba 1108 analyzer. The purity of the compounds were confirmed by thin layer chromatography using silica gel glass plates and a solvent system of benzene: ethanol (8:2). The spots were developed in iodine chamber and visualized under ultra violet lamp.

\section{Synthesis of substituted phenyl urea [2a-21]}

$p$-Substituted aniline (1a-1L; $0.1 \mathrm{~mol})$ was dissolved in $10-50 \mathrm{~mL}$ of glacial acetic acid and volume was made upto $100 \mathrm{~mL}$ with water. To this sodium cyanate $(6.5 \mathrm{~g}, 0.1 \mathrm{~mol})$ in $50 \mathrm{~mL}$ of warm water was added with constant stirring. Solution was allowed to stand for $60 \mathrm{~min}$. then cooled in ice and filtered with suction and dried. Physico-chemical data and m.p. of the synthesized products were in agreement with the data reported in the literature ${ }^{11,12}$. 


\section{Synthesis of substituted phenyl semicarbazides [3a-31]}

Equimolar quantity of substituted phenyl urea $(0.1 \mathrm{~mol})$ and hydrazine hydrate $(0.1 \mathrm{~mol} ; 5 \mathrm{ml})$ in ethanol under alkaline condition $(\mathrm{NaOH}, 4 \mathrm{~g})$ were refluxed for $4-10 \mathrm{~h}$ with stirring. Excess of ethanol was distilled off under vacuum and then poured into ice. The obtained product was filtered and recrystallized from $90 \%$ aqueous ethanol. Generally compounds exhibited IR (KBr) $v_{\max } 3450,1650,3269,840 \mathrm{~cm}^{-1} .{ }^{1} \mathrm{HNMR} \delta$ 7.2-7.5 (m, 4H, Ar-H), 8.26 (s, 1H, Ar-NH).

\section{Synthesis of 2-propyl-benzoxazin-4-one (6)}

Anthranilic acid $(0.1 \mathrm{~mol})$ was refluxed with butyric anhydride for $2 \mathrm{~h}$. Excess of anhydride was distilled off by vacuum distillation to obtain the precipitate of $N$-propyl anthranilic acid. $N$ propyl anthranilic acid (5) was further refluxed with acetic anhydride for $2 \mathrm{~h}$ to get 2-propylbenzoxazin-4-one (6).

\section{Synthesis of title compounds [H1-H12]}

The title compounds were synthesized following procedure reported earlier ${ }^{7}$. To a solution of 2propyl-benzoxazin-4-one $(0.01 \mathrm{M})$, substituted phenyl semicarbazides $(3 \mathrm{a}-3 \mathrm{~L} ; 0.01 \mathrm{M})$ in glacial acetic acid was added and refluxed for $4 \mathrm{~h}$. Obtained reaction mixture was poured into crushed ice and left overnight. The solid which separated out was filtered, washed with cold distilled water, dried and recrystallized from hot ethanol. The yield, melting point and other physical properties of synthesized compounds are recorded in Table 6 .

\section{Pharmacology}

All the experiments were carried out according to protocols approved by the Institutional Animal Ethical Committee, Dr. H. S. Gour University, Sagar (Committee registration number = 379/01/ab/CPCSEA, Letter reference number $=$ Animal ethical committee/07/DB/274 dated 02-11-07, Candidate number $=09$ ). Male albino mice (CF-1 strain or swiss, 18-25 g) and rats (Sprague-Dawley or Wistar, 100-150 g) were used as experimental animals. The tested compounds were suspended in polyethylene glycol 400 .

\section{Behavioral testing}

The titled compounds $(100 \mathrm{mg} / \mathrm{kg})$ were screened for their behavioral effect using actophotometer ${ }^{13}$ at $30 \mathrm{~min}$ and $1 \mathrm{~h}$ after drug administration. The behavior of animals inside the photocell was recorded as a digital score. Increased scores suggest good behavioral (locomotor) activity. The activity of the compounds were at maximum at $1 \mathrm{~h}$, therefore, the activity values at $1 \mathrm{~h}$ were used to calculate $\%$ decrease in locomotor activity. The control group animals were administered PEG 400. The observations are tabulated in Table 3. 
Table 6. Physical data of 1-(4-substituted-phenyl)-3-(4-oxo-2-propyl-4H-quinazolin-3-yl)-urea (H1-H12)

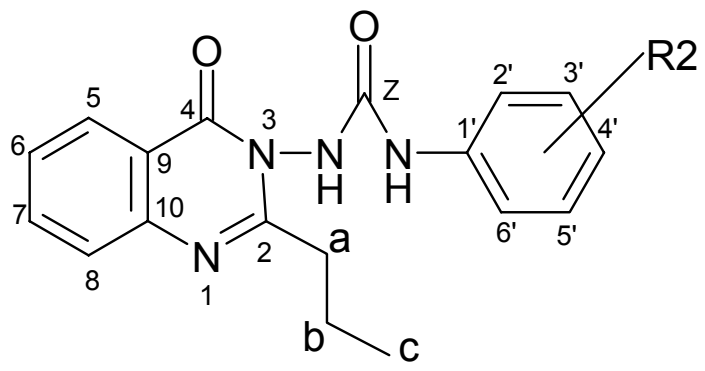

\begin{tabular}{|c|c|c|c|c|c|}
\hline $\begin{array}{l}\text { Code } \\
\text { No. }\end{array}$ & $\mathrm{R} 2$ & $\begin{array}{l}\text { Yield } \\
(\%)\end{array}$ & m.p. $\left({ }^{\circ} \mathrm{C}\right)$ & Mol. formula & $\begin{array}{c}\text { Element }^{\mathrm{a}} \\
(\text { Calculated } \% / \text { Found } \% /)\end{array}$ \\
\hline $\mathrm{H} 1$ & $-\mathrm{H}$ & 46 & 210 & $\mathrm{C}_{18} \mathrm{H}_{18} \mathrm{~N}_{4} \mathrm{O}_{2}$ & $\begin{array}{c}\mathrm{N}(17.38 / 17.35) \\
\mathrm{C}(67.07 / 67.04) \\
\mathrm{H}(5.63 / 5.61)\end{array}$ \\
\hline $\mathrm{H} 2$ & $-F$ & 55 & 236 & $\mathrm{C}_{18} \mathrm{H}_{17} \mathrm{FN}_{4} \mathrm{O}_{2}$ & $\begin{array}{c}\mathrm{N}(16.46 / 16.45) \\
\mathrm{C}(63.52 / 63.50) \\
\mathrm{H}(5.03 / 5.0)\end{array}$ \\
\hline H3 & $-\mathrm{Cl}$ & 54 & 234 & $\mathrm{C}_{18} \mathrm{H}_{17} \mathrm{ClN}_{4} \mathrm{O}_{2}$ & $\begin{array}{c}\mathrm{N}(15.70 / 15.66) \\
\mathrm{C}(60.59 / 60.55) \\
\mathrm{H}(4.80 / 4.78)\end{array}$ \\
\hline $\mathrm{H} 4$ & $-\mathrm{Br}$ & 49 & $>300^{\mathrm{b}}$ & $\mathrm{C}_{18} \mathrm{H}_{17} \mathrm{BrN}_{4} \mathrm{O}_{2}$ & $\begin{array}{c}\mathrm{N}(13.96 / 13.95) \\
\mathrm{C}(53.88 / 53.86) \\
\mathrm{H}(4.27 / 4.25)\end{array}$ \\
\hline H5 & $-\mathrm{I}$ & 36 & 231 & $\mathrm{C}_{18} \mathrm{H}_{17} \mathrm{IN}_{4} \mathrm{O}_{2}$ & $\begin{array}{c}\mathrm{N}(12.50 / 12.49) \\
\mathrm{C}(48.23 / 48.20) \\
\mathrm{H}(3.82 / 3.79)\end{array}$ \\
\hline H6 & $-\mathrm{NO}_{2}$ & 45 & 224 & $\mathrm{C}_{18} \mathrm{H}_{17} \mathrm{~N}_{5} \mathrm{O}_{4}$ & $\begin{array}{c}\mathrm{N}(19.82 / 19.80) \\
\mathrm{C}(57.79 / 57.76) \\
\mathrm{H}(4.66 / 4.63)\end{array}$ \\
\hline $\mathrm{H} 7$ & $o-\mathrm{CH}_{3}(\mathrm{~d})$ & 69 & 229 & $\mathrm{C}_{19} \mathrm{H}_{20} \mathrm{~N}_{4} \mathrm{O}_{2}$ & $\begin{array}{c}\mathrm{N}(16.66 / 16.65) \\
\mathrm{C}(67.84 / 67.83) \\
\mathrm{H}(5.99 / 5.95)\end{array}$ \\
\hline $\mathrm{H} 8$ & $m-\mathrm{CH}_{3}(\mathrm{~d})$ & 64 & 225 & $\mathrm{C}_{19} \mathrm{H}_{20} \mathrm{~N}_{4} \mathrm{O}_{2}$ & $\begin{array}{c}\mathrm{N}(16.66 / 16.65) \\
\mathrm{C}(67.84 / 67.81) \\
\mathrm{H}(5.99 / 5.94)\end{array}$ \\
\hline H9 & $p-\mathrm{CH}_{3}(\mathrm{~d})$ & 70 & 220 & $\mathrm{C}_{19} \mathrm{H}_{20} \mathrm{~N}_{4} \mathrm{O}_{2}$ & $\begin{array}{c}\mathrm{N}(16.66 / 16.65) \\
\mathrm{C}(67.84 / 67.82) \\
\mathrm{H}(5.99 / 5.95)\end{array}$ \\
\hline
\end{tabular}




\begin{tabular}{cccccc}
$\mathrm{H} 10$ & $-\mathrm{CH}_{2}(\mathrm{~d})-$ & 52 & 228 & $\mathrm{C}_{20} \mathrm{H}_{22} \mathrm{~N}_{4} \mathrm{O}_{2}$ & $\mathrm{~N}(15.99 / 15.96)$ \\
& $\mathrm{CH}_{3}(\mathrm{e})$ & & & $\mathrm{C}(68.55 / 68.53)$ \\
& & & & $\mathrm{H}(6.33 / 6.30)$ \\
$\mathrm{H} 11$ & $-\mathrm{OCH}_{3}(\mathrm{~d})$ & 56 & $>300^{\mathrm{b}}$ & $\mathrm{C}_{19} \mathrm{H}_{20} \mathrm{~N}_{4} \mathrm{O}_{3}$ & $\mathrm{~N}(15.90 / 15.89)$ \\
& & & & $\mathrm{C}(64.76 / 64.75)$ \\
& & & & $\mathrm{H}(5.72 / 5.69)$ \\
$\mathrm{H} 12$ & $-\mathrm{O} \mathrm{CH}_{2}(\mathrm{~d})-$ & 60 & $>300^{\mathrm{b}}$ & $\mathrm{C}_{20} \mathrm{H}_{22} \mathrm{~N}_{4} \mathrm{O}_{3}$ & $\mathrm{~N}(15.29 / 15.25)$ \\
& $\mathrm{CH}_{3}(\mathrm{e})$ & & & & $\mathrm{C}(65.56 / 65.55)$ \\
& & & & $\mathrm{H}(6.05 / 6.01)$ \\
\hline
\end{tabular}

${ }^{\mathrm{a}}$ Elemental analyses for $\mathrm{C}, \mathrm{N}$ and $\mathrm{H}$ were within $\pm 0.4 \%$ of the theoretical value. ${ }^{\mathrm{b}}$ Melting point of the compound at their decomposition.

\section{CNS depressant activity}

The forced swim pool method described earlier ${ }^{14}$ was followed. Wistar rats were placed in chamber (diameter $45 \mathrm{~cm}$, height $20 \mathrm{~cm}$ ) containing water up to a height of $15 \mathrm{~cm}$ at $25 \pm 2{ }^{\circ} \mathrm{C}$. Two swim sessions were conducted for initial $15 \mathrm{~min}$ pre test, followed by a 5 min test session $24 \mathrm{~h}$ later. The animals were administrated $(100 \mathrm{mg} / \mathrm{kg})$ test compounds (i.p.) $30 \mathrm{~min}$ before the test session. The period of immobility (passive floating without struggling, making only those movements which are necessary to keep head above the surface of water) during the 5 min test period were measured. The results are presented in Table 4.

\section{Phenobarbitone induced hypnosis potentiation test}

The drug solution in polyethylene glycol (PEG 400) was administered in a dose of $100 \mathrm{mg} / \mathrm{kg}$ to a group of 6 animals. Thirty minutes after drug administration, animals were injected Phenobarbitone sodium. The animals fell asleep on their back. Sleeping time of each rat was taken as the interval between the loss and return of the righting reflex as indicated by inability or ability, respectively, of the rat to right itself in 3 successive trials when placed on its back. The time taken by animals to awake was noted. A control was also performed after pre-treatment with test substance vehicle. The results are reported in Table 5.

\section{Acknowledgements}

Thanks are due to SAIF, Lucknow for performing spectroscopic studies.

\section{References}

1. Hazarkhani, H.; Karima, B. Tetrahedron 2003, 59, 4757.

2. Armarego, W. L. F. Adv. Heterocyclic Chem. 1979, 24, 1 
3. Fisnerova, L.; Brunova, B.; Kocfeldova Z.; Tikalova J.; Maturova E.; Grimova, J. Collect. Czech. Chem.Commun. 1991, 56, 2373.

4. Gravier, D.; Dupin, J. P.; Casadebaig, F.; Hou, G.; Boisseau, M.; Bernard, H. Pharmazie 1992, 47, 91.

5. Boltze, K. H.; Dell, H. D.; Lehwald, H.; Loranz, D.; Ruberg-Schweer, M. ArzneimForsch./Drug Res. 1963, 13, 688.

6. Wolfe, J. F.; Rathman, T. L.; Sleevi, M. C.; Campbell, J. A.; Greenwood, T. D. J. Med. Chem. 1990, 33, 161.

7. Jatav, V.; Mishra, P.; Kashaw, S.; Stables, J. P. Eur. J. Med. Chem. 2008, 43, 135.

8. Jatav, V.; Mishra, P.; Kashaw, S.; Stables, J. P. Accepted in Eur. J. Med. Chem. (doi:10.1016/j.ejmech.2007.12.003).

9. Pandeya, S.N.; Aggarwal, N.; Jain, J. S. Pharmazie 1999, 54, 300.

10. Pandeya, S. N.; Mishra, V.; Singh, P. N.; Rupainwar, D. C. Pharmacol. Res. 1998, 37, 17.

11. Aggarwal, N.; Mishra, P. J. Pharm. Pharmaceutical Sci. 2004, 7, 260.

12. Aggarwal, N.; Mishra, P. J. Zhejiang Uni. 2005, 6B, 617.

13. Boissoer, J. R.; Simon, P. Arch. Int. Pharmacodyn. Ther. 1965, 158, 212.

14. Porsolt, R. D.; Anton, G.; Blanet, N.; Jalbre, M. Eur. J. Pharmacol. 1978, 47, 379. 